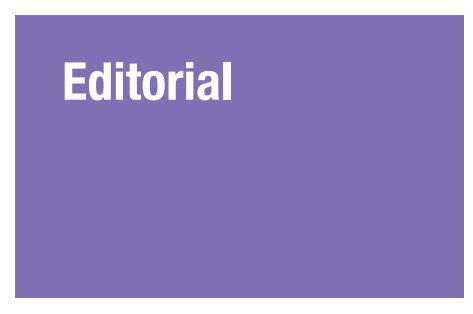

Submitted: 26 Nov 2018

Accepted: 7 Dec 2018

Online: 28 Dec 2018

\section{Malaysian Journal of Medical Sciences' Performance Status in 2017 and the Challenges}

\author{
Nour Azimah Zulkapli', Jafri Malin Abdullah ${ }^{2}$
}

1 Production Editor, Malaysian Journal of Medical Sciences, Universiti Sains Malaysia, 1180 o USM, Pulau Pinang, Malaysia

2 Chief Editor, Malaysian Journal of Medical Sciences, Universiti Sains Malaysia Health Campus, 16150 Kubang Kerian, Kelantan, Malaysia

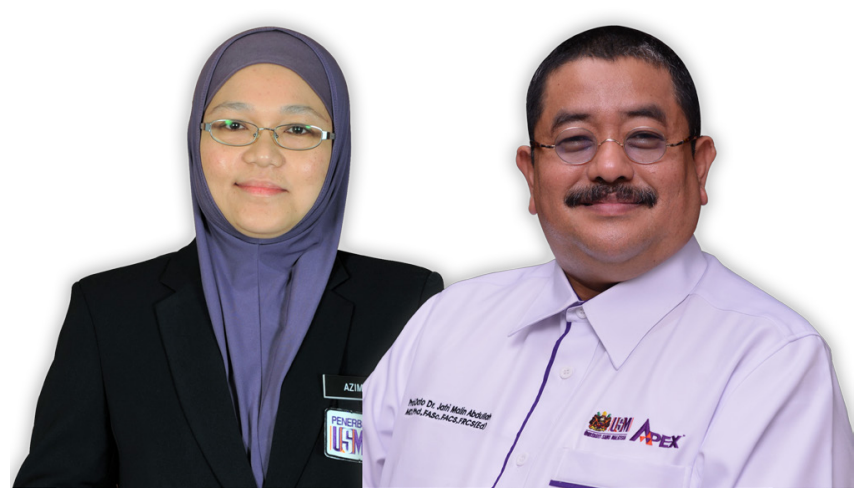

To cite this article: Nour Azimah Z, Abdullah JM. Malaysian Journal of Medical Sciences' performance status in 2017 and the challenges. Malays J Med Sci. 2018;25(6):1-5. https://doi.org/10.21315/mjms2018.25.6.1

To link to this article: https://doi.org/10.21315/mjms2018.25.6.1

\begin{abstract}
This report presents a review of the Malaysian Journal of Medical Sciences' (MJMS) performance status throughout 2017, which covers the submission pattern of original manuscripts by month, the geographical distribution of submitting authors, the types of manuscripts and overall acceptance/rejection rates.

As the years progress, MJMS continues to receive an escalating number of manuscript submissions. This contributes to an ever-increasing workload, which makes administrative tasks continually more challenging. Although the manuscript submission platform seeks to minimise the pre-publication workload of the journal administrator, it is still a time-consuming task, particularly when authors seek exclusive attention for their submitted manuscripts.
\end{abstract}

Keywords: challenge, performance, submissions, workload, administrator

\section{Introduction}

As expected, the number of original manuscripts sent to the Malaysian Journal of Medical Sciences (MJMS) via our electronic submission system, ScholarOne Manuscripts ${ }^{\mathrm{TM}}$, has shown an increase of $17.5 \%$, from 301 manuscripts in 2016 (1) to 365 manuscripts in
2017. This increment proves that the existence of MJMS is recognised by medical peer groups in other parts of the world. Moreover, all researchers are concerned with publication in scientific journals, as they are the most important medium for the dissemination of their work (2). 


\section{Submission Pattern by Month}

2017 witnessed an unpredictable number of monthly manuscript submissions. On average, at least 30 manuscripts were received each month, with a high of 40 received in the month of August. Other peak months included January, February, April and October (Figure 1).

\section{Submission by Geography}

Malaysia has remained the top manuscript contributor, with 154 submissions (42.2\%). Table 1 shows that the number of manuscripts submitted by Malaysian authors is more than double those submitted from Iran. As seen in Table 1, India has fallen to third place, compared to 2016, when the country used to be listed in second place, followed by Iran in third (1). Indonesia is in fourth place with 32 submissions, followed by Nigeria with 22. The rest included those with a minimum of one submission.

\section{Submission by Manuscript Type}

Out of 365 manuscripts submitted in 2017, 'Original Article' manuscripts were the most common, with 273 submissions in 2017 compared to 213 submissions in 2016 (1). 'Review Article' manuscripts were the second most submitted, followed by 'Brief Communications' manuscripts (Figure 2).

\section{The Acceptance/Rejection Rate of Manuscripts}

Figure 3 was constructed based on the data of manuscripts with decision dates between Jan 1, 2017 and Dec 31, 2017. The percentage of rejections occupies a huge portion in the pie chart where $50.3 \%$ of rejections were due to decisions made by the Editor-in-Chief based on collective reviews, while $17 \%$ were due to the inappropriateness of the scope or content of the study. Whereas, $23.7 \%$ were sent back for major

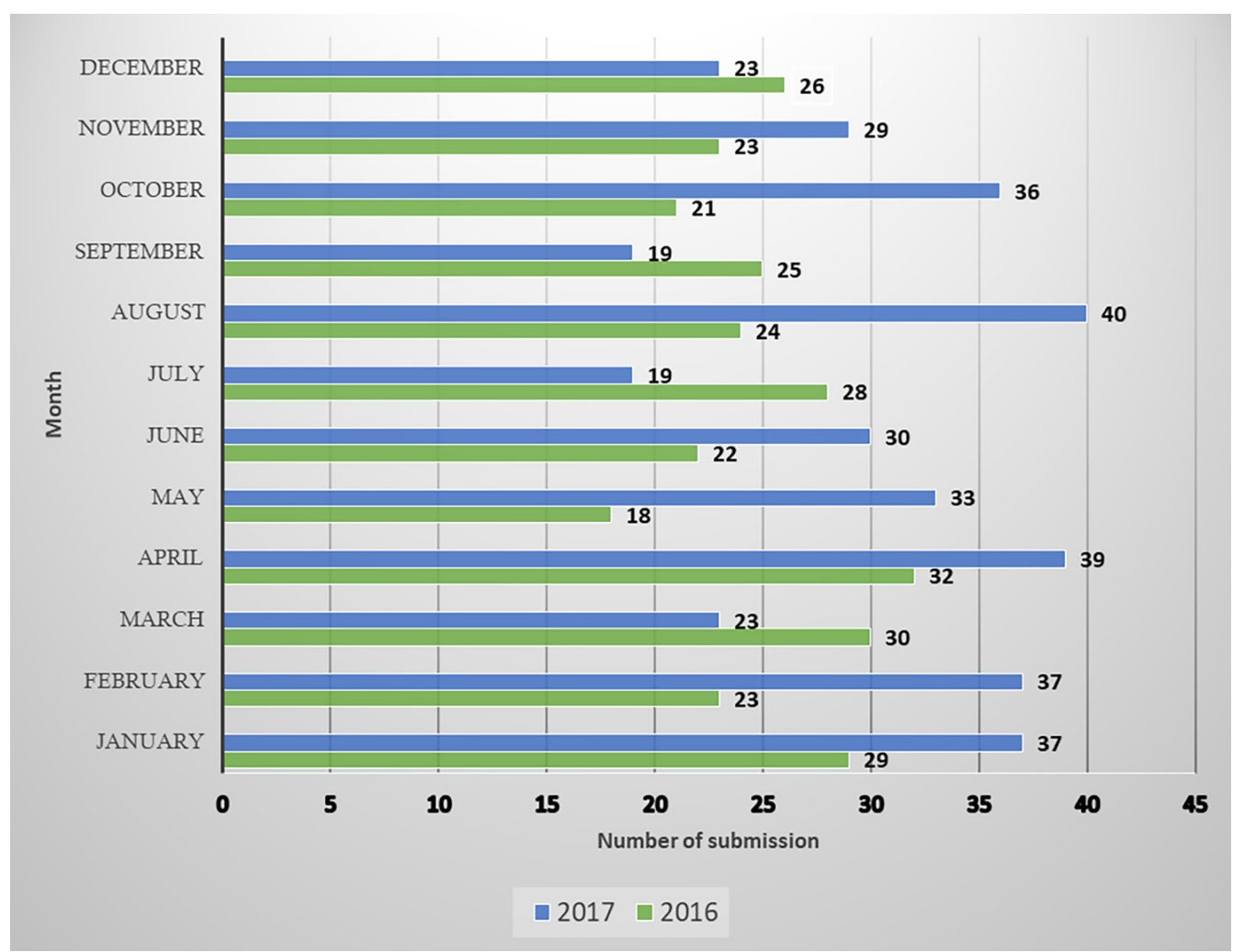

Figure 1. Information based on original manuscripts submitted via ScholarOne Manuscripts ${ }^{\mathrm{TM}}$ system in 2016 and 2017

Source: https://mc.manuscriptcentral.com/maljms 
Editorial | MJMS' performance status in 2017 and the challenges

Table 1. Number and percentage of manuscripts submitted, listed by country of submitting author

\begin{tabular}{|c|c|c|}
\hline Country of Submitting Author & Manuscripts & Percentage \\
\hline Malaysia & 154 & $42.2 \%$ \\
\hline Iran (the Islamic Republic of) & 60 & $16.4 \%$ \\
\hline India & 47 & $12.9 \%$ \\
\hline Indonesia & 32 & $8.8 \%$ \\
\hline Nigeria & 22 & $6.0 \%$ \\
\hline Iraq & 5 & $1.4 \%$ \\
\hline Saudi Arabia & 5 & $1.4 \%$ \\
\hline Turkey & 5 & $1.4 \%$ \\
\hline Pakistan & 4 & $1.1 \%$ \\
\hline Brunei Darussalam & 3 & $0.8 \%$ \\
\hline Thailand & 3 & $0.8 \%$ \\
\hline Egypt & 2 & $0.5 \%$ \\
\hline Germany & 2 & $0.5 \%$ \\
\hline Italy & 2 & $0.5 \%$ \\
\hline Japan & 2 & $0.5 \%$ \\
\hline Nepal & 2 & $0.5 \%$ \\
\hline Oman & 2 & $0.5 \%$ \\
\hline Algeria & 1 & $0.3 \%$ \\
\hline Aruba & 1 & $0.3 \%$ \\
\hline Australia & 1 & $0.3 \%$ \\
\hline Bangladesh & 1 & $0.3 \%$ \\
\hline Cyprus & 1 & $0.3 \%$ \\
\hline Kazakhstan & 1 & $0.3 \%$ \\
\hline Mexico & 1 & $0.3 \%$ \\
\hline Palestine, State of & 1 & $0.3 \%$ \\
\hline Russian Federation & 1 & $0.3 \%$ \\
\hline South Africa & 1 & $0.3 \%$ \\
\hline Spain & 1 & $0.3 \%$ \\
\hline United Kingdom of Great Britain and Northern Ireland & 1 & $0.3 \%$ \\
\hline Total & 365 & $100 \%$ \\
\hline
\end{tabular}

Source: https://mc.manuscriptcentral.com/maljms

revision, which is proportionately high compared to $8.3 \%$ slated for minor revision. Only $0.7 \%$ of post-reviewed manuscripts were accepted for publication. These figures show that MJMS is really concerned with quality rather than quantity.

\section{Challenges Faced by the Journal Administrator}

Submission of research manuscripts is a much easier process today because of online submission systems like ScholarOne, Editorial Manager and Evise $^{\circledR}$ used by publishers all over the world (3). These systems work in a largely similar way, and are meant to make the publishing process more efficient and readily accessible to both authors and reviewers.

On the other side of things, however, the journal administrator faces increasing challenges along the journey of journal publication, when finding solutions and technical troubleshooting become additional tasks alongside juggling the responsibilities of being a copy editor, production editor and system administrator.

One recurring difficulty is time pressure. This is defined as the subjective feeling of having less time than required to complete a task. It arises each time the journal administrator has to perform a long list of tasks which must keep moving in order to meet deadlines. This includes having to respond to queries by authors through emails while the queue of new submitted 
manuscripts continues to build up, and keeping authors updated when they insist on exclusive attention. The reality is that everyone wants their manuscript to be entertained first. Last but not least, the administrator must deal with imperfect manuscripts which do not meet the journal's requirements as given in its guidelines.
Based on a study by Moore and Tenney (4), time pressure generally impairs performance because it places constraints on our capacity for thought and action which limit exploration and increase reliance on well-learned or heuristic strategies. Thus, time pressure increases performance speed, but at the expense of quality.

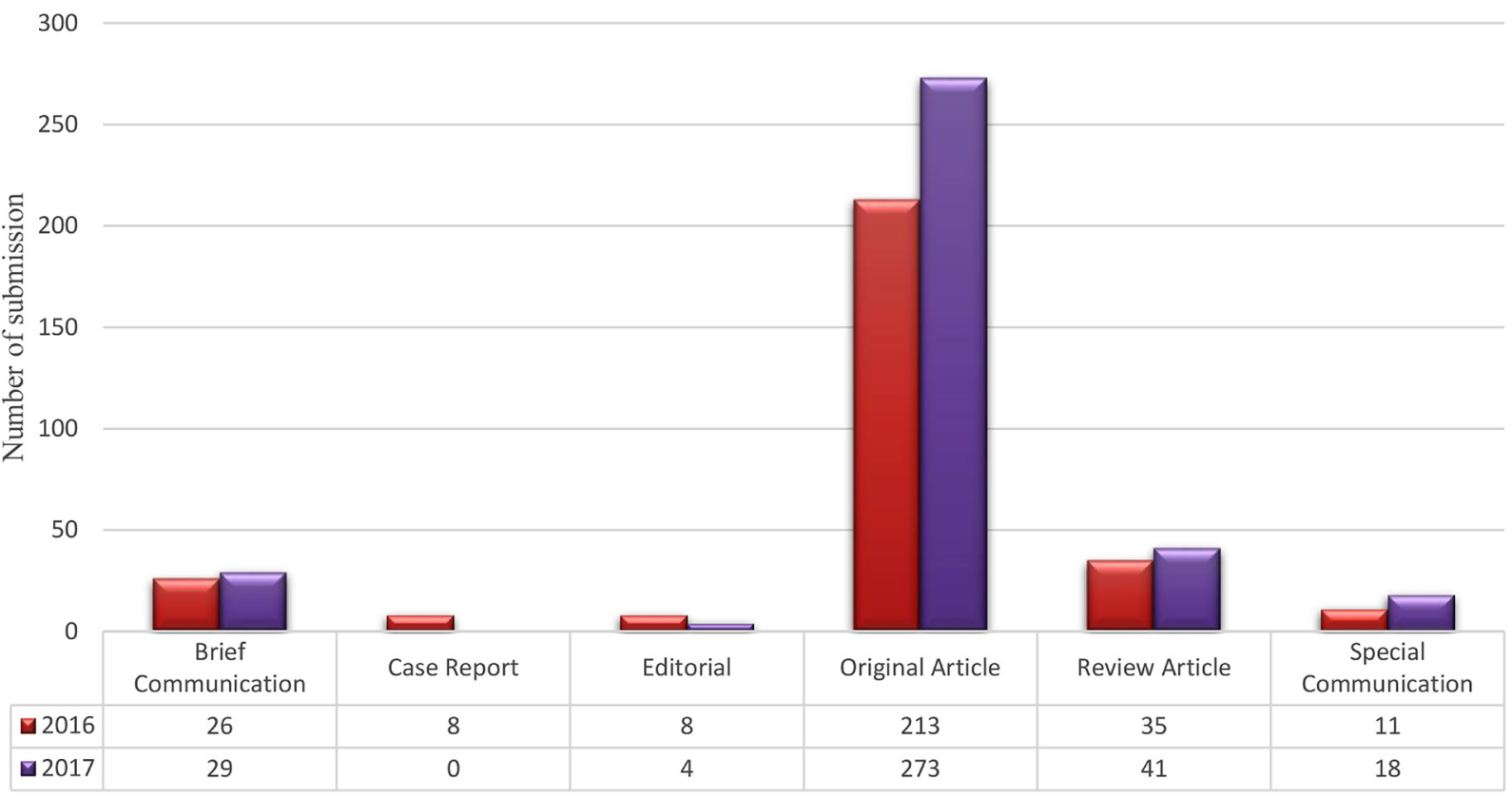

Figure 2. Number of manuscript submissions by type

Source: https://mc.manuscriptcentral.com/maljms

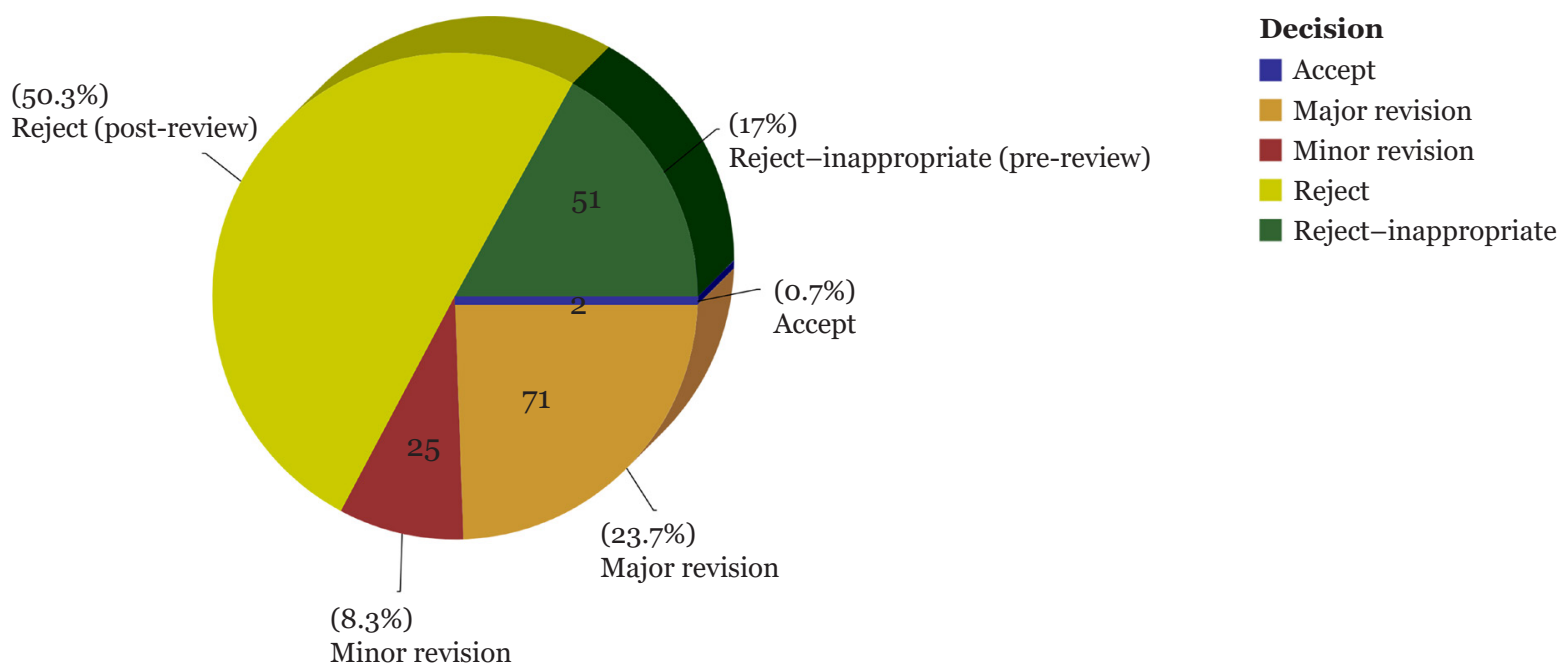

Figure 3. Percentage and number of manuscripts by decision submitted between Jan 1, 2017 and Dec 31, 2017; decision date is between Jan 1, 2017 and Dec 31, 2017

Grouped by: Manuscript Decision

Source: https://mc.manuscriptcentral.com/maljms 
Editorial | MJMS' performance status in 2017 and the challenges

\section{Acknowledgements}

None

\section{Correspondence}

Ms Nour Azimah Zulkapli

BSc Biology (Hons) (USM)

Editorial Office,

Malaysian Journal of Medical Sciences,

Penerbit Universiti Sains Malaysia,

Universiti Sains Malaysia,

11800 USM, Pulau Pinang, Malaysia.

Tel: +604 6534448

Fax: +604 6575714

E-mail:mjms.usm@gmail.com

\section{References}

1. Nour Azimah Z, Jafri Malin A. Malaysian Journal of Medical Sciences' performance status in 2016. Malays $J$ Med Sci. 2017;24(6):1-4. https://doi. org/10.21315/mjms2017.24.6.1

2. Ajami S, Movahedi F. Challenges for authors and publishers in scientific journal. Pak $\mathrm{J} \mathrm{Med}$ Sci. 2013;29(Suppl 1):432-436. https://doi. org/10.12669/pjms.291(Suppl).3550

3. Enago Academy. How do online manuscript submission systems work? https://www.enago. com/academy/how-do-online-manuscriptsubmission-systems-work/

4. Moore DA, Tenney ER. Time pressure, performance and productivity. UK: Emerald Group Publishing Limited; 2012. pp 305-326. Retrieved from http://www.emeraldinsight.com/ doi/abs/10.1108/S1534-0856(2012)0000015015 